\title{
Panorama do ensino de Ergonomia e da Acessibilidade nos cursos de Arquitetura e Urbanismo das Instituições de Ensino Superior públicas brasileiras
}

\author{
Overview of the Teaching of Ergonomics and Accessibility in the \\ courses of Architecture and Urbanism of Brazilian Public Higher \\ Education Institutions
}

CLEYTON LUIZ DA SILVA ROSA

Mestrando, Universidade Federal de Juiz de Fora, cleyton.rosa@arquitetura.ufjf.br

FREDERICO BRAIDA

Doutor, Universidade Federal de Juiz de Fora/ Universidade Tecnológica Federal do Paraná

- Toledo, frederico.braida@arquitetura.ufjf.br

NATÁLIA COBUCI ANTUNES

Graduanda, Universidade Federal de Juiz de Fora, natalia.cobuci@arquitetura.ufjf.br

\section{RESUMO}

Este artigo aborda a temática do ensino da Ergonomia e da Acessibilidade nos cursos de Arquitetura e Urbanismo no Brasil. Ele é fruto de uma pesquisa que partiu da seguinte questão: Como tem se configurado o ensino da Ergonomia e da Acessibilidade na formação de arquitetos e urbanistas brasileiros? O principal objetivo é apresentar um panorama do ensino dessas disciplinas nos cursos de Arquitetura e Urbanismo no Brasil, adotando-se como recorte as instituições públicas de ensino superior. Metodologicamente, foi realizada uma análise de conteúdo das matrizes curriculares dos cursos de Arquitetura e Urbanismo oferecidos pelas 65 instituições de ensino superior públicas brasileiras, a partir da coleta dos dados disponíveis no Cadastro e-MEC. Ao final, pode-se verificar que, embora essas temáticas estejam cada vez mais presentes, ainda há que se fazer um esforço maior para uma incorporação plena dos saberes vinculados à Ergonomia e à Acessibilidade na formação de arquitetos e urbanistas.

PALAVRAS-CHAVE: Ergonomia, Acessibilidade, Arquitetura e Urbanismo, ensino

\section{ABSTRACT}

This article addresses the topic of teaching Ergonomics and Accessibility in Architecture and Urbanism courses in Brazil. It is the result of research that started with the following question: How has the teaching of Ergonomics and Accessibility have been configured in the training of Brazilian architects 


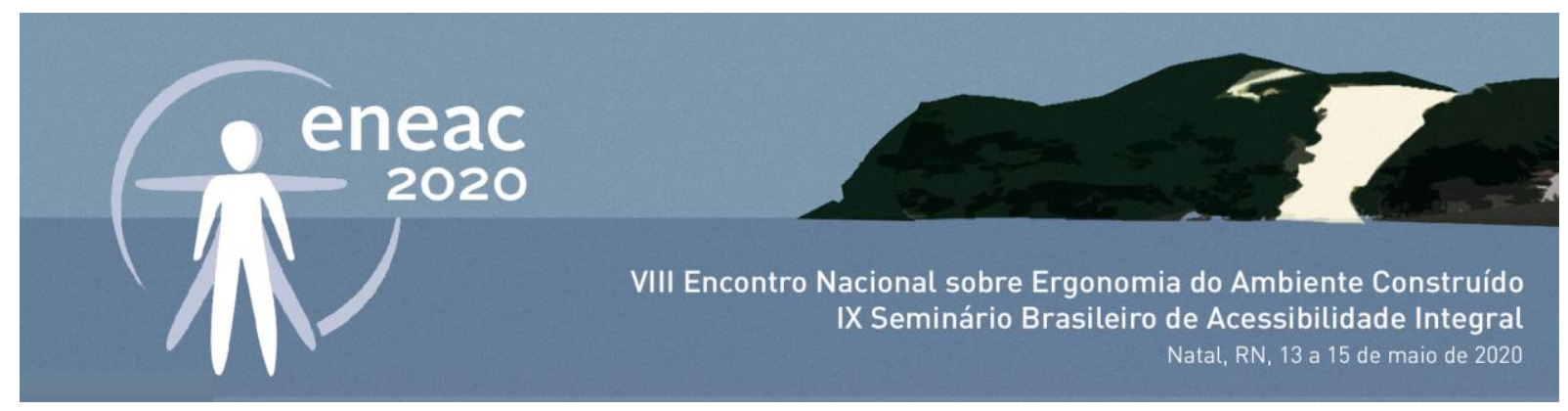

and urban planners? The main aim is to present an overview of the teaching of these disciplines in the courses of Architecture and Urbanism in Brazil, adopting undergraduate public institutions as elements of analysis. Methodologically, a content analysis of the curricular matrices of the Architecture and Urbanism courses offered by 65 Brazilian public institutions was carried out, based on the collection of data available in the e-MEC database. In the end, it can be seen that, although these themes are increasingly present, there is still a greater effort to fully incorporate knowledge related to Ergonomics and Accessibility in the undergraduate of architects and urban planners.

KEYWORDS: Ergonomics, Accessibility, Architecture and Urbanism, teaching

\section{INTRODUÇÃO}

O processo de formação profissional dos arquitetos e urbanistas no contexto brasileiro é descrita na forma das leis educacionais como uma formação que deve primar pela generalidade dos campos que compõem a área, "abrangendo o urbanismo, a edificação, o paisagismo, bem como a conservação e a valorização do patrimônio construído, a proteção do equilíbrio do ambiente natural, e a utilização racional dos recursos disponíveis" (BRASIL, 2010). Tal direcionamento é regido pelas Diretrizes Curriculares Nacionais (DCN), única para todo o território brasileiro, as quais orientam a estruturação dos cursos de Arquitetura e Urbanismo.

Segundo o Instituto dos Arquitetos do Brasil (2016), o ensino acadêmico de Arquitetura iniciou-se em 12 de agosto de 1816, com o decreto de criação da Escola Real de Ciências, Artes e Ofícios (primeiro curso de arquitetura do Brasil), tendo, desde essa época, sofrido modificações na "forma de ensinar, de construir e até mesmo de pensar a arquitetura". Infere-se que a profissão de arquitetoi, formalmente, foi inaugurada pelo Decreto Federal no 23.569, de 11 de dezembro de 1933, que regulamentou o exercício das profissões do arquiteto, do engenheiro e do agrimensor, bem como através das Resoluções no 218/1973 e no 1.010/2005. Com a Resolução n 3, de 25 de junho de 1969, do Conselho Federal de Educação, houve uma busca por um currículo mínimo para os cursos de Arquitetura e Urbanismo, objetivando uma lógica de formação única e mais equalizada para todo o Brasil. Com a Portaria MEC no 1.770, de 21 de dezembro de 1994, foram estabelecidas as DCN para estruturação dos cursos de Arquitetura e Urbanismo. Mais recentemente, a Lei no 12.378, de 31 de dezembro de 2010, regulamentou o exercício da profissão de arquiteto e urbanista no país, com a criação do Conselho de Arquitetura e Urbanismo (CAU), separando-se do Conselho de Engenharia, Arquitetura e Agronomia (CREA).

De acordo com Alonso, Freire e Panet $(2008$, p. 2), o ensino de Arquitetura e Urbanismo é desafiador devido principalmente à "característica multidisciplinar da profissão de arquiteto, que incorpora atributos e conhecimentos de outros campos cognitivos, na intenção de conseguir sua expressão máxima". Além disso, as questões socioculturais caracterizam-se como imprescindíveis ao exercício responsável da profissão. De certo modo, o desafio de projetar para os vários sujeitos possíveis, cuja condição é diferente de quem projeta, demanda dos projetistas um conhecimento e um aprofundamento sobre as especificidades dos sujeitos/usuários e também da forma como eles interagem com o mundo. Vale ressaltar que, por vezes, as realidades dos sujeitos para os quais os 


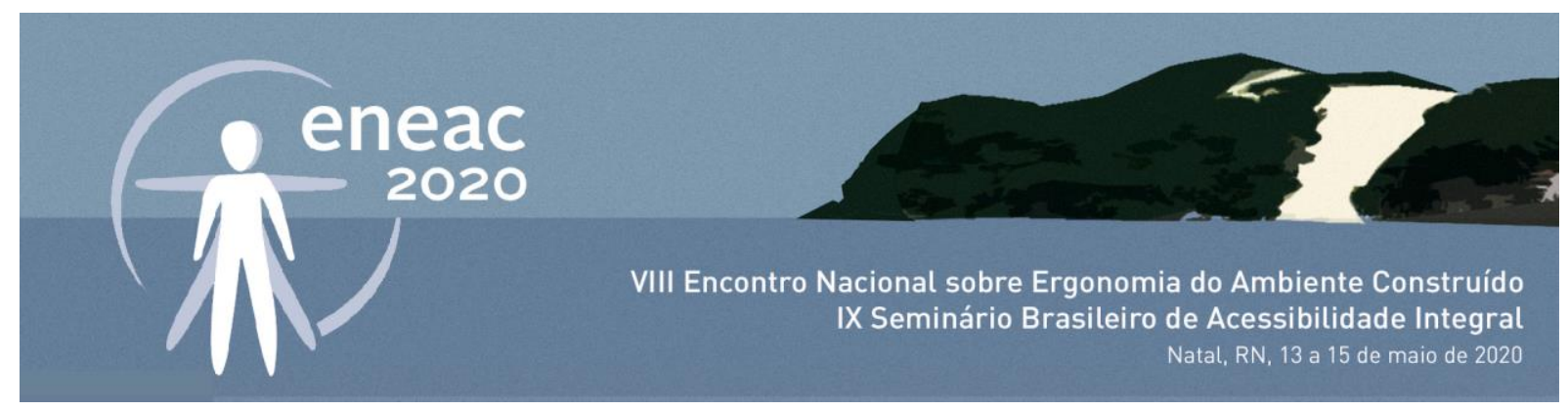

projetos são realizados são desconhecidas dos projetistas; assim, as ações de vivência são eficazes para um conhecimento e uma comunicação mais efetiva (ALONSO; FREIRE; PANET, 2008, p. 2).

Nesse contexto, pode-se verificar que algumas temáticas, dentre as quais se destacam a Ergonomia e a Acessibilidade, demandam um grande envolvimento por parte dos docentes e dos discentes na formação de profissionais conscientes, éticos e comprometidos com a sociedade como um todo. Essas temáticas já não podem mais estar circunscritas às formalidades dos Projeto Político Pedagógico dos cursos (PPC) - há que se converter em práticas efetivas, capazes de sensibilizar os alunos e formá-los plenamente como profissionais que tragam essas temáticas de forma intrínseca em seus projetos. É nesse sentido que o presente artigo partiu da seguinte questão: Como tem se configurado o ensino da Ergonomia e da Acessibilidade na formação de arquitetos e urbanistas brasileiros?

Metodologicamente, este artigo é fruto de uma pesquisa quali-quantitativa, em que foi realizada uma análise de conteúdo das matrizes curriculares dos cursos de Arquitetura e Urbanismo oferecidos pelas 65 instituições de ensino superior públicas brasileiras, a partir da coleta dos dados disponíveis no Cadastro e-MEC. Portanto, foram consultados os PPC dos cursosii, a fim de se compreender como as temáticas da Ergonomia e da Acessibilidade têm sido abordadas como componentes curriculares.

O principal objetivo é apresentar um panorama do ensino dessas disciplinas nos cursos de Arquitetura e Urbanismo no Brasil, adotando-se como recorte as instituições de ensino superior públicas. Assim, espera-se contribuir com a evidenciação de como essas temáticas têm sido apropriadas pelas instituições públicas de ensino superior brasileiras no âmbito da formulação de suas propostas curriculares e pedagógicas para a formação de arquitetos e urbanistas no país.

\section{CONTEXTUALIZAÇÃO/CONCEITUAÇÃO SOBRE O CAMPO DA ERGONOMIA E DA}

\section{ACESSIBILIDADE NO BRASIL}

Especialmente a partir dos anos de 1980, o tema da acessibilidade tem atraído a atenção dos pesquisadores e dos profissionais de diversas áreas, dentre as quais merecem destaque a Arquitetura, o Urbanismo, o Design, a Ergonomia e as Engenharias. Desde então, conceitos como Desenho Universal, Inclusão Social e Acessibilidade entraram na pauta de reflexões que visam à melhoria da qualidade do ambiente construído e ocupado pelos seres humanos (BRAIDA et al., 2014, p. 165).

Em busca de uma sociedade mais justa e inclusiva (CORRÊA, 2008), a inserção de pessoas com deficiências (sejam elas temporárias ou permanentes) no cotidiano urbano tornou-se uma necessidade premente. Seja por força de Lei ou reflexo de uma consciência coletiva inclusiva, observa-se que já não se pode mais pensar o espaço urbano sem contemplar, em sua plenitude, mesmo que possam parecer utópico, os temas supracitados, sobretudo quando se trata de espaços abertos ao público. É nesse sentido que os temas da Ergonomia e da Acessibilidade (ainda que tardiamente) têm ganhado maior projeção nas estruturas curriculares dos cursos de Arquitetura e Urbanismo no Brasil (ROSA; BRAIDA; COBUCCI, 2019, p. 111).

Para a International Ergonomics Association, "a Ergonomia (ou Fatores Humanos) é uma disciplina científica relacionada ao entendimento das interações entre os seres humanos e outros elementos 


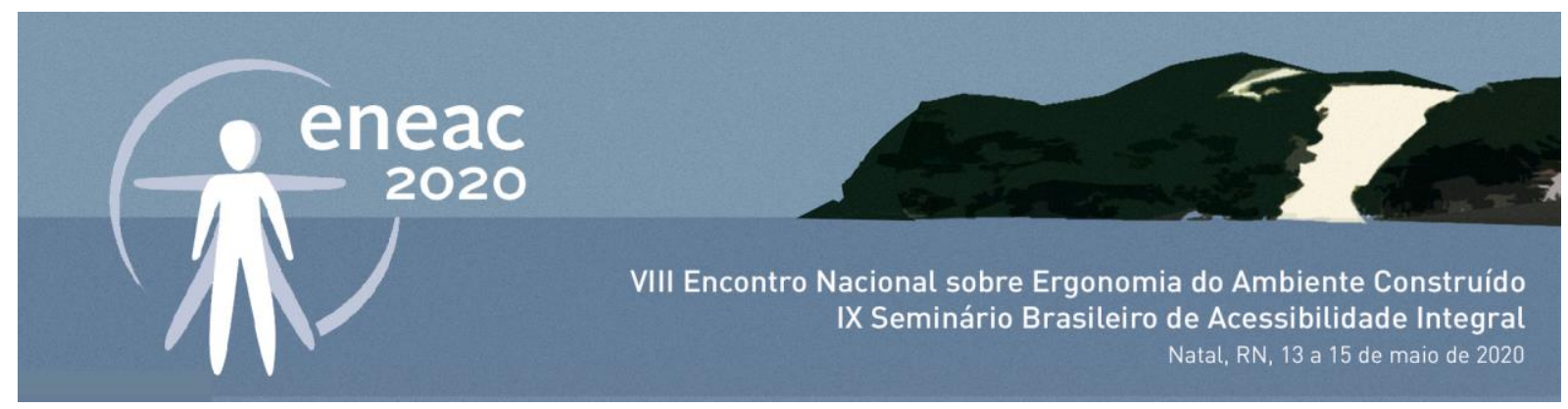

ou sistemas, e à aplicação de teorias, princípios, dados e métodos a projetos a fim de otimizar o bemestar humano e o desempenho global do sistema" (ASSOCIAÇÃO BRASILEIRA DE ERGONOMIA, [s.d.]). Para Barbosa e Guimarães (2009), há uma indefinição sobre o surgimento da Ergonomia. No entanto, existe quase que uma unanimidade entre os principais estudiosos que o seu nascimento se deu, grosso modo, em um contexto de evolução tecnológica e na busca de forma sistemática de entender a relação entre seres humanos e o sistema no qual o sujeito está inserido. Esse processo se intensificou, sobretudo, com o aparecimento e utilização com mais pujança das máquinas (ABRAHÃO; PINHO, 2002; BARBOSA; GUIMARÃES, 2009). Para Karwowski (1996 apud MORAES; MONT'ALVÃO, 2012, p. 20), a Ergonomia é uma "disciplina científica que trata da interação entre os homens e a tecnologia. Integra o conhecimento das ciências humanas para adaptar tarefas, sistemas, produtos e ambientes às habilidades e limitações físicas e mentais das pessoas".

Abrahão e Pinho (2002, p. 47) alertam que a "Ergonomia é uma disciplina jovem, em evolução, e que vem reivindicando o status de ciência". Ademais, Gurgel (2002, p. 89) aponta que

$$
\begin{aligned}
& \text { não podemos mais aceitar projetos de ambientes que não respeitem as proporções do corpo humano } \\
& \text { nem suas limitações. Espaços mal projetados, com soluções inapropriadas aos seus usuários, são } \\
& \text { sinônimos de falta de pesquisa e entendimento das necessidades relacionadas à realização de tarefas } \\
& \text { específicas. Proporcionar conforto e bem estar [sic.] deve ser o objetivo primordial de qualquer projeto. }
\end{aligned}
$$

Outrossim, dentre as diversas conceituações para a Acessibilidade, merece destaque aquela proposta por Dischinger e Bins Ely (2006), que afirmam que a acessibilidade é a possibilidade de deslocar para algum lugar de forma independente, confiável e com conforto, entendendo como este espaço organiza todas as relações espaciais que acontecem no local, podendo qualquer indivíduo participar de forma ativa das atividades e de todos os equipamentos. Elas também asseguram que os componentes para que um espaço seja considerado acessível são: informação, deslocamento, uso e comunicação.

Empiricamente, pode-se dizer que, no Brasil, houve uma maior preocupação com a acessibilidade após a realização dos chamados grandes (ou mega) eventos que aconteceram no país durante as duas primeiras décadas deste milênio, ainda que não se perceba uma acessibilidade plena em nossas cidades. Alguns desses grandes eventos foram: os Jogos Pan-Americanos (2007), a Jornada Mundial da Juventude (JMJ) (em 2013), Copa do Mundo (em 2014) e, mais recentemente, os Jogos Olímpicos e Paralímpicos (em 2016). Os altos padrões internacionais estabelecidos e os olhares cada mais atentos às adequações de acessibilidade exigiram uma série de ações. No evento religioso JMJ, atentou-se para a adaptação dos "meios de comunicação oficiais, o acesso aos Atos Centrais, hospedagem e transporte" (SHIMOSAKEI, 2013). Já na Copa do Mundo, buscou-se adequar o entorno dos estádios e cuidar da mobilidade urbana nas 12 cidades-sede (BRASIL, 2011). Em 2016, para os Jogos Olímpicos, evento realizado pelo Comitê Olímpico Internacional e Comitê Paralímpico Internacional, foram realizadas adequações de calçadas, pavimentação em concreto na entrada dos principais locais turísticos, de rampas e também de todas as estruturas que eram existentes; além disso, houve o monitoramento e construções de outros espaços esportivos atendendo à acessibilidade (PREFEITURA..., 2015).

Segundo Moraes (2007, p. 17), por "muito tempo os espaços foram, e muitos ainda são, projetados sem levar em consideração o homem como ser passível de limitações no desempenho de atividades". De acordo com Baptista (2003 apud MOARES, 2007, p. 26-29), havia quatro estágios 


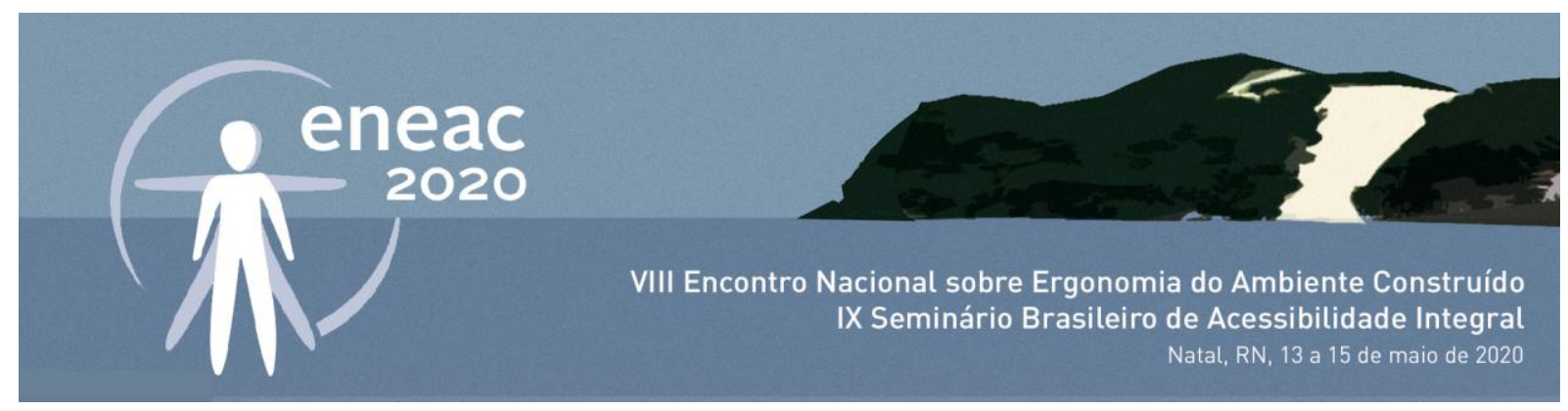

quando se tratava sobre a evolução dos projetos de ambientes focados na acessibilidade espacial: (1) Projetos sem adequação: "as pessoas com deficiência eram postas à margem da sociedade", sendo, em muitos casos, sacrificadas, tal como era bastante comum na antiguidade greco-romana; (2) Projetos para segregação: "estágio caracterizado por uma eugenia sanitarista, onde as pessoas com deficiência eram, quase sempre, enviadas a asilos, hospícios e outras unidades de saúde especializadas", características do século XIX; (3) Projetos acessíveis de caráter exclusivo: "os projetos livres de barreiras eram muito limitados em sua concepção" e as barreiras atitudinais e informacionais eram ignoradas; e (4) Projetos universais de caráter inclusivo: estágio em que "o conceito de acessibilidade torna-se mais abrangente" e os projetos são "cada vez mais seguros, confortáveis, favorecendo a autonomia dos usuários dos ambientes, independente de suas limitações ou habilidades".

Segundo a versão de 2004 da Norma Técnica "Acessibilidade a edificações, mobiliário, espaços e equipamentos urbanos", a NBR 9050, da Associação Brasileira de Normas Técnicas (ABNT), a acessibilidade era definida como "possibilidade e condição de alcance, percepção e entendimento para a utilização com segurança e autonomia de edificações, espaço, mobiliário, equipamento urbano e elementos" (ASSOCIAÇÃO BRASILEIRA DE NORMAS TÉCNICAS, 2004, p. 2). Já em 2015, com a sua atualização, vê-se que a associação incorporou uma série de elementos:

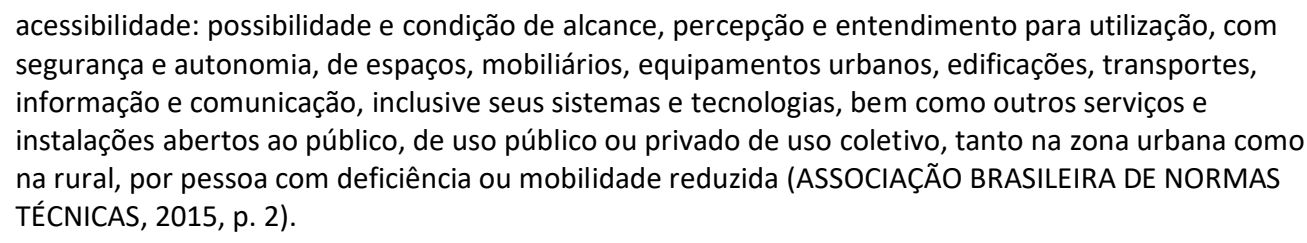

acessibilidade: possibilidade e condição de alcance, percepção e entendimento para utilização, com segurança e autonomia, de espaços, mobiliários, equipamentos urbanos, edificações, transportes, informação e comunicação, inclusive seus sistemas e tecnologias, bem como outros serviços e instalações abertos ao público, de uso público ou privado de uso coletivo, tanto na zona urbana como na rural, por pessoa com deficiência ou mobilidade reduzida (ASSOCIAÇÃO BRASILEIRA DE NORMAS TÉCNICAS, 2015, p. 2).

Dentre as estruturais alterações realizadas na norma, estão as seguintes mudanças: acrescentou-se a possibilidade de utilização de "transportes, informação e comunicação, incluindo sistemas e tecnologias, na zona urbana ou rural"; a definição de locais que obrigatoriamente têm de ter acessibilidade (espaços de uso público ou privado de uso coletivo); e ressaltou-se a inclusão da expressão "zona urbana como na rural", que fez o entendimento do conceito ser alargado, ao menos em norma, para as zonas rurais.

Como se vê, a própria conceituação da Acessibilidade ainda se encontra em processo de construção. É, portanto, fundamental que os conjuntos de saberes que dizem respeito à Ergonomia e à Acessibilidade sejam incorporados aos currículos das escolas de Arquitetura e Urbanismo, sobretudo com vistas a subsidiar os projetos que busquem soluções inovadoras para o ambiente construído e que superem as barreiras arquitetônicas que, recorrentemente, dão causa aos processos de exclusão.

\section{ERGONOMIA E ACESSIBILIDADE NO AMBIENTE CONSTRUÍDO E AS ATRIBUIÇÕES DOS ARQUITETOS E URBANISTAS}

Dentre as várias atribuições profissionais dos arquitetos e urbanistas, está a atividade de concepção de projetos de ergonomia e de acessibilidade. Segundo o Anuário de Arquitetura e Urbanismo do Conselho de Arquitetura e Urbanismo, foram executados 10.286 projetos envolvendo a acessibilidade no ano de 2018, sendo 5.762 projetos de adequação de acessibilidade, 2.494 de 


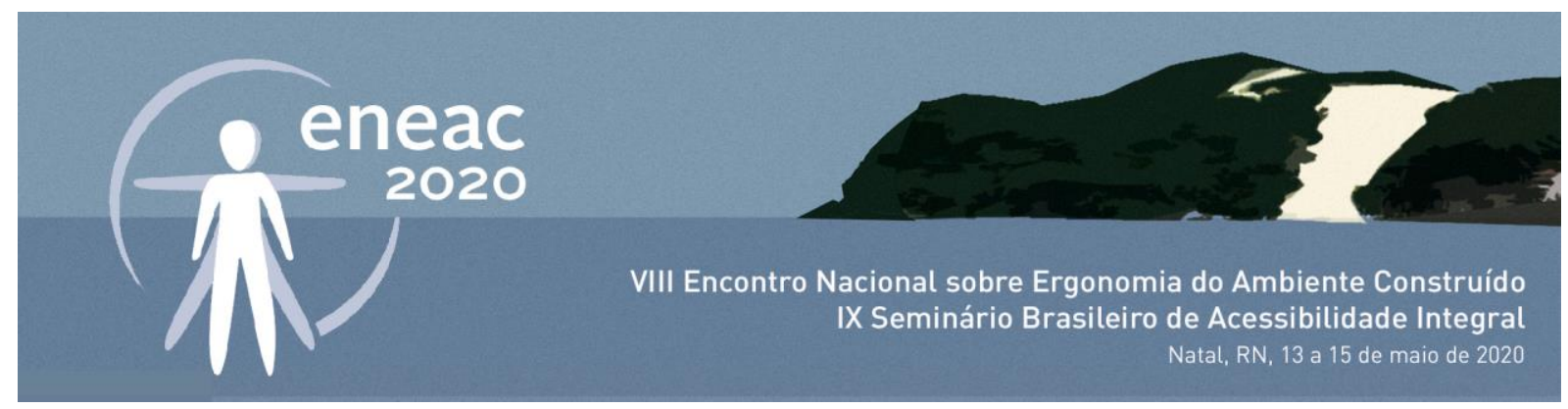

projeto de sistema viário e acessibilidade, 1.494 de execução de adequação de acessibilidade, 536 de execução de sistema viário e acessibilidade, representando um aumento de $18 \%$ do número total de projetos em 2018, se comparados com 2017; o projeto com maior crescimento, tendo em vista o ano anterior, foi o projeto de sistema viário e acessibilidade, que teve $43,42 \%$ de crescimento (CONSELHO DE ARQUITETURA E URBANISMO DO BRASIL, 2019).

Além disso, fica claro também nas DCN do curso de graduação em Arquitetura e Urbanismo, resolução $n$ ㅇ 2, de 17 de junho de 2010, que esse curso deve possibilitar uma formação profissional mínima, habilitando este profissional para "conceber projetos de arquitetura, urbanismo e paisagismo e para realizar construções, considerando [...] [fatores] ambientais e de acessibilidade dos usuários" (BRASIL, 2010). Na resolução de 2010, não é mencionado o termo "ergonomia", porém, vê-se um esforço atual demonstrado, sobretudo com a nova proposta de diretrizes curriculares nacionais do curso de graduação em Arquitetura e Urbanismo, votada no XXXVII ENSEA Encontro Nacional sobre Ensino de Arquitetura e XX CONABEA - Congresso da ABEA, em 2019, que também incorpora a Ergonomia como elemento fundamental profissional do Arquiteto e Urbanista.

Art. 110 O curso deverá estabelecer ações pedagógicas visando ao desenvolvimento de conhecimentos, habilidades, competências e atitudes com responsabilidade técnica, artística e social que compreendam, pelo menos:

[...] VII. as habilidades e competências necessárias e os conhecimentos especializados para conceber projetos e executar obras de arquitetura, urbanismo e arquitetura da paisagem, em todas as suas escalas, de modo a incorporar as exigências culturais, econômicas, estéticas, técnicas, ambientais, de segurança, de desempenho, de ergonomia, e de acessibilidade e mobilidade dos usuários (ENCONTRO NACIONAL SOBRE ENSINO DE ARQUITETURA E URBANISMO, 2019).

Essa mesma proposta incorpora a ergonomia e a acessibilidade como exigências que devem ser contempladas nos processos projetuais:

Art. 15 Os conteúdos de Projeto de Arquitetura, Projeto de Arquitetura de Interiores, Projeto de Urbanismo e Projeto de Arquitetura da Paisagem compreendem o conjunto organizado dos conhecimentos científicos, empíricos e intuitivos relativos ao espaço construído, etapas e processos projetuais de elaboração de programas de necessidades, concepção, expressão e representação, estudos, definição de processos e técnicas construtivas, detalhamentos e soluções executivas para obras de Arquitetura, Arquitetura de Interiores, Urbanismo, Arquitetura da Paisagem; e os processos projetuais, a partir do entendimento da cadeia produtiva da construção civil e das necessidades da sociedade, devem incorporar as exigências culturais, econômicas, estéticas, simbólicas, técnicas, ambientais, de segurança, de desempenho, de ergonomia, e de acessibilidade e mobilidade dos habitantes (ENCONTRO NACIONAL SOBRE ENSINO DE ARQUITETURA E URBANISMO, 2019, grifos nossos).

Castro e Rheingantz $(2005$, p. 2 ) apresentam uma posição conciliadora entre Arquitetura e Ergonomia, evidenciando a necessidade de inter-relação entre ambas para a qualidade do ambiente construído.

A adequação do espaço aos seus usuários é uma preocupação da Ergonomia, e também da Arquitetura. A diferença é que a ergonomia enfoca as atividades realizadas e a arquitetura prioriza a ocupação e distribuição do ambiente, bem como a emoção e os referenciais históricos dos usuários. Portanto as duas áreas de conhecimentos abordam pontos importantes, sendo que uma não deve ser preterida em relação a outra. Ambas devem ser consideradas durante o processo de concepção (CASTRO; RHEINGANTZ, 2005, p. 2).

Com essa afirmação de Castro e Rheingantz (2005), sublinhamos, inicialmente, o quanto a ergonomia é um elemento fundamental para ser pensada no projeto, logo devendo ser seus conhecimentos 


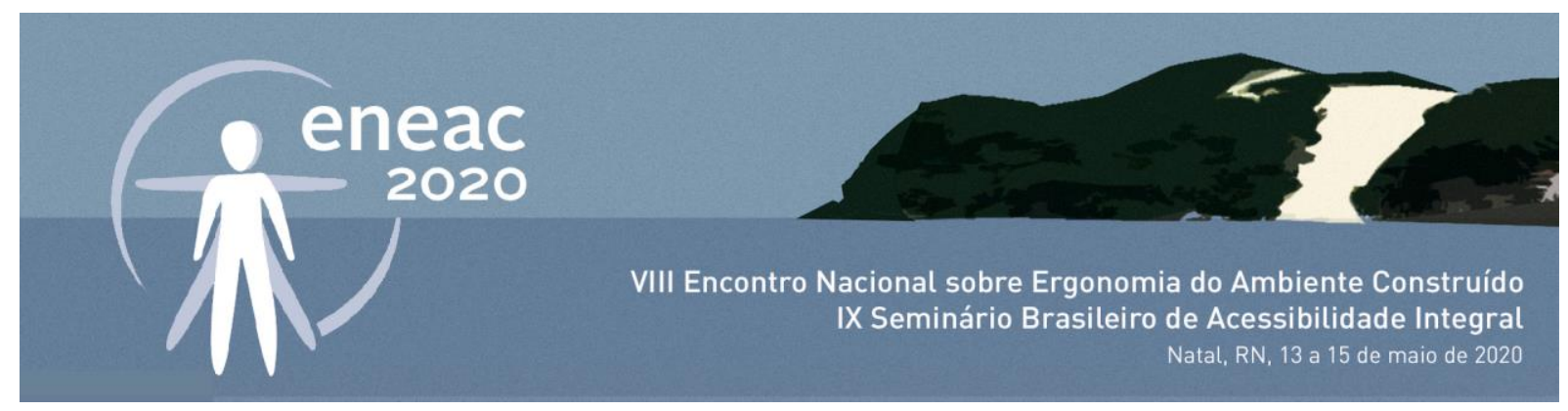

incorporados à graduação em Arquitetura e Urbanismo, seja na forma de disciplina ou qualquer outro elemento de ensino.

\section{PROCEDIMENTOS E MÉTODOS}

Este artigo é fruto de uma pesquisa quali-quantitativa, tanto exploratória quanto descritiva, realizada pelo Grupo de Pesquisa em Arquitetura de Interiores, Design \& Decoração e Grupo de Pesquisa das Linguagens e Expressões da Arquitetura, do Urbanismo e do Design - LEAUD, vinculados ao Programa de Pós-graduação em Ambiente Construído e às Faculdades de Engenharia e Arquitetura e Urbanismo da Universidade Federal de Juiz de Fora, cujo objetivo geral foi compreender como tem se dado a formação dos estudantes da graduação em Arquitetura e Urbanismo quanto às temáticas da ergonomia e da acessibilidade, especificamente nas IES públicas do país.

Considerando-se os procedimentos de coleta de dados, bem como as fontes consultadas, pode-se dizer que este artigo é derivado de uma pesquisa bibliográfica e documental. Durante a fase de revisão bibliográfica, foram pesquisados artigos científicos, manuais, notícias jornalísticas e legislações específicas que dizem respeito às temáticas da acessibilidade e de ergonomia.

A coleta de dados se deu na base digital de livre acesso via Internet intitulada Cadastro e-MEC. Por meio dessa base, mantida pelo Ministério da Educação, chegou-se aos PPC dos cursos selecionados. Uma vez criado um banco de dados específico para o recorte da pesquisa, procedeu-se à análise de conteúdo das matrizes curriculares constantes nos PPC. Algumas pesquisas foram complementadas diretamente nos sites das Instituições, os quais, por vezes, apresentavam matrizes curriculares mais bem detalhadas ou informações mais completas.

Ao todo, foram 65 instituições selecionadas. Nas análises dos PPC, focou-se nas disciplinas Acessibilidade e Ergonomia, atentando-se para: (a) a existência da disciplina cujos títulos tangenciam a "Acessibilidade", "DU", "Ergonomia" e correlatas; (b) carga horária despendida para as temáticas; e (c) modalidade de oferta da disciplina: optativa, eletiva, obrigatória ou especial.

Posteriormente, foi realizado um levantamento mais aprofundado das disciplinas encontradas nos PPC, segundo os seguintes critérios: (a) ementa; (b) bibliografias utilizadas; e (c) editora da publicação. Com as bibliografias, foi realizada uma análise bibliométrica e foram reveladas as publicações e os autores mais utilizados nas disciplinas dos cursos. Foi adotada a seguinte escala de classificação: (a) "autores citados de forma muito frequente", para autores citados mais de sete vezes; (b) "autores citados de forma medianamente frequente", para autores que foram citados entre seis e três vezes em bibliografias, inclusive; e (3) "autores citados de forma pouco frequente", para menos de três citações.

De forma específica, ao final, foram realizadas uma análise descritiva e uma análise comparativa entre as universidades, a fim de identificar em quantas e em quais cursos públicos de Arquitetura e Urbanismo do país tais temáticas foram abordadas e em qual modalidade se apresentavam. Para realizar tais análises, foram usadas as denominações dadas às disciplinas (Ergonomia, Acessibilidade, Ergonomia e Acessibilidade), assim como a classificação segundo sua modalidade: obrigatória, eletiva, optativa. 


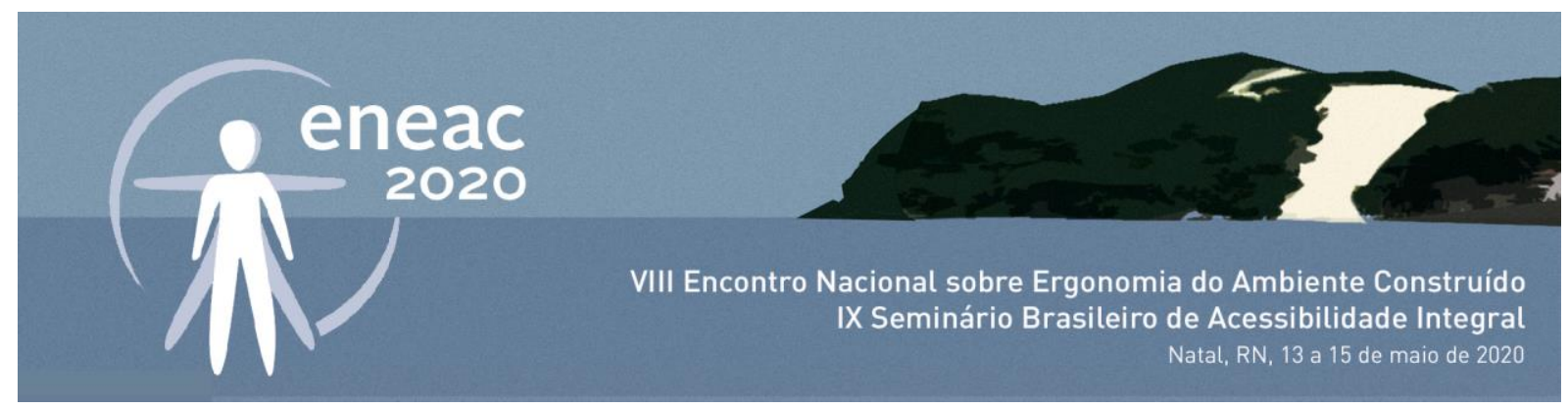

\section{RESULTADOS, LIMITAÇõES E POSSIBILIDADES}

Conforme o levantamento dos PPC das 65 instituições pesquisadas, verificou-se que grande parte não oferece as disciplinas de Acessibilidade e Ergonomia em nenhuma modalidade (obrigatória, eletiva, optativa ou especial).

Quanto à forma que as disciplinas são nomeadas, encontrou-se 12 denominações distintas, que podem ser vistas na Tabela 1. Vê-se que um grupo de seis instituições (UFS, UNESP, UFPB, UNIFAB, USP e UNB) oferecem disciplinas que possuem a palavra "Ergonomia" no título. Um ponto comum entre essas instituições é que elas utilizam, em suas bibliografias básicas, pelo menos uma das referências mais citadas, (e mais utilizadas) entre as instituições pesquisadas, como ABNT, lida, Panero e Grandjean. Dessas seis disciplinas, somente uma é ofertada na modalidade obrigatória.

Tabela 1: Denominação das disciplinas de Ergonomia

\begin{tabular}{c|c} 
Denominação da disciplina & $\begin{array}{c}\text { número de vezes que } \\
\text { aparece em grades }\end{array}$ \\
\hline Ergonomia & 7 \\
\hline Ergonomia e acessibilidade & 6 \\
\hline Ergonomia no/do ambiente construído & 2 \\
\hline Conforto Ambiental (com ênfase em Ergonomia) & 2 \\
\hline Dimensionamento dos Espaços da Habitação & 2 \\
\hline Ergonomia aplicada ao design (I e II) & 1 \\
\hline Ergonomia na Arquitetura & 1 \\
\hline Ergonomia do/no espaço construído e habitado & 1 \\
\hline Ergonomia aplicada à arquitetura de interiores & 1 \\
\hline Ergonomia Aplicada ao Planejamento e Projeto do Mobiliário Urbano & 1 \\
\hline Tópicos especiais em ergonomia & \\
\hline
\end{tabular}

Fonte: dos Autores.

Quanto à denominação das disciplinas de Acessibilidade, foram encontradas 10 variações de denominação, sendo a mais adotada pelas instituições o termo "Ergonomia e acessibilidade", conforme Tabela 2. Outra porção de disciplinas traz o termo Acessibilidade precedido sempre pela ênfase adotada em cada instituição: ambiental, segurança das edificações, predial e urbana, construção civil e ambiente construído.

\begin{tabular}{|c|c|}
\hline Denominação da disciplina & $\begin{array}{l}\text { número de vezes que } \\
\text { aparece em grades }\end{array}$ \\
\hline Ergonomia e acessibilidade & 7 \\
\hline Acessibilidade ambiental & 3 \\
\hline Acessibilidade e segurança de/das edificações & 2 \\
\hline Acessibilidade & 2 \\
\hline Conforto Ambiental I: Ergonomia e Acessibilidade & 1 \\
\hline Desenho Universal & 1 \\
\hline Acessibilidade predial e urbana & 1 \\
\hline Acessibilidade na construção civil & 1 \\
\hline O indivíduo e o espaço & 1 \\
\hline Acessibilidade no ambiente construído & 1 \\
\hline
\end{tabular}




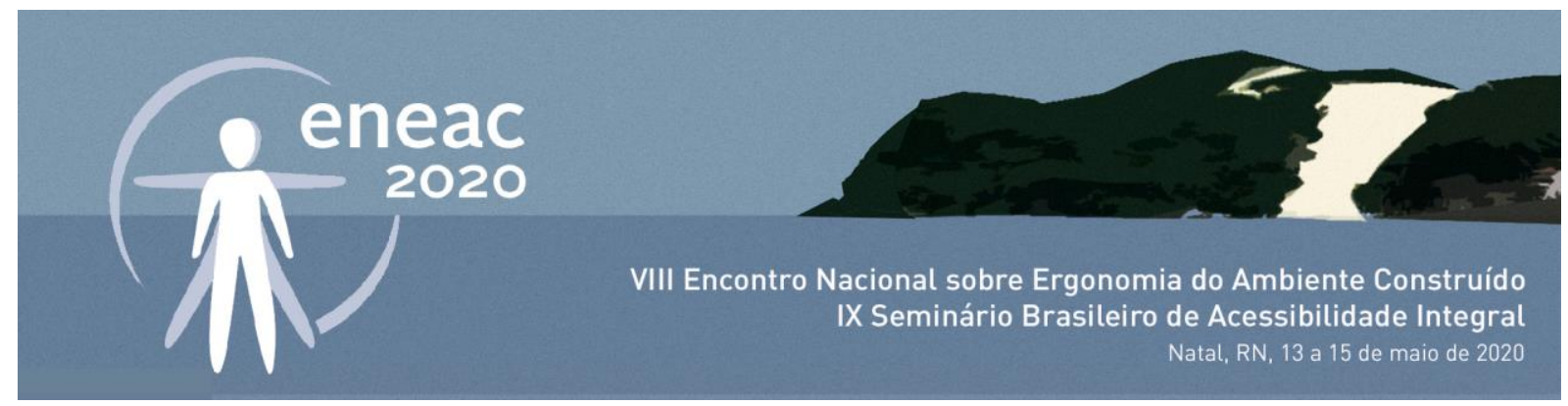

No que tange à periodização das disciplinas de Acessibilidade e Ergonomia (Figura 1), observa-se que, de uma forma geral, quando as disciplinas são obrigatórias, elas estão em maior parte no início ou até o meio do curso. Quando as disciplinas são ofertadas na modalidade eletiva ou optativa, percebese que há uma priorização pela segunda porção do curso, do 50 ao 70 período. Somente uma instituição, a USP, menciona como período ideal para as disciplinas o período final do curso. Destacase também que, nas disciplinas de final de curso da USP, nas quatro disciplinas que compõem o currículo, vê-se um grande aprofundamento, como metodologias de análises Ergonômica do Trabalho, noções de esforço físico e Biomecânica Ocupacional, conteúdos os quais saem bastante do comum das disciplinas que estão nas porções iniciais dos cursos.

Figura 1: Periodização das disciplinas de Ergonomia (à esquerda) e de Acessibilidade (à direita)

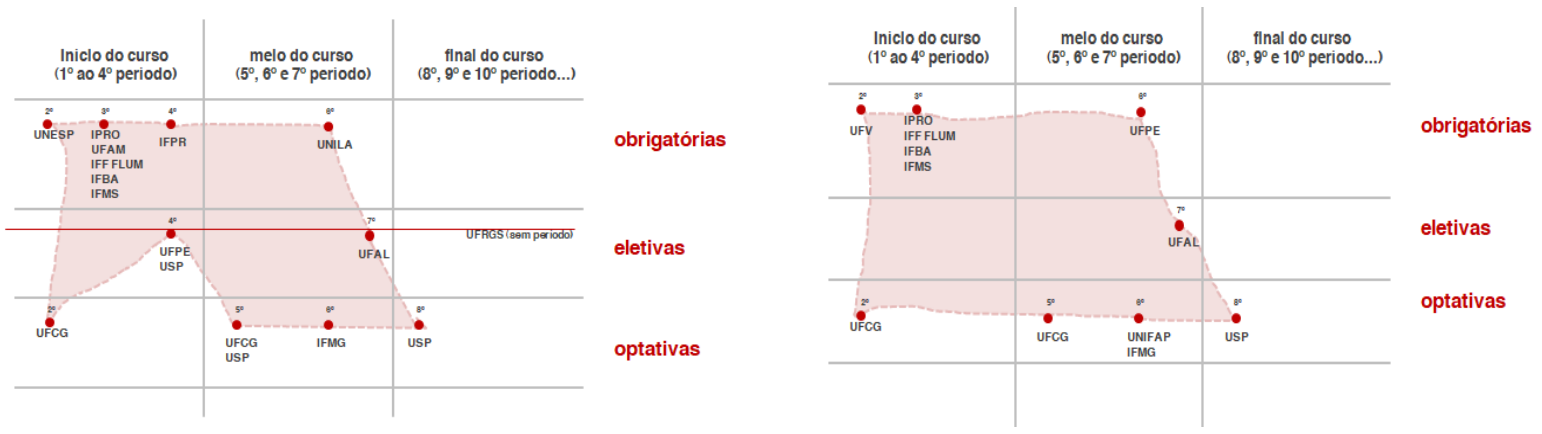

Fonte: dos Autores.

Conforme observa-se na Figura 2, é possível identificar que, dentre as disciplinas analisadas, a porcentagem em horas, quando comparada com as cargas horárias totais dos cursos, é muito pequena, demonstrando que tais temas possuem uma abordagem em horas bastante inferior do que outros temas.

Figura 2: Porção da carga horária total do curso com relação às disciplinas abordadas

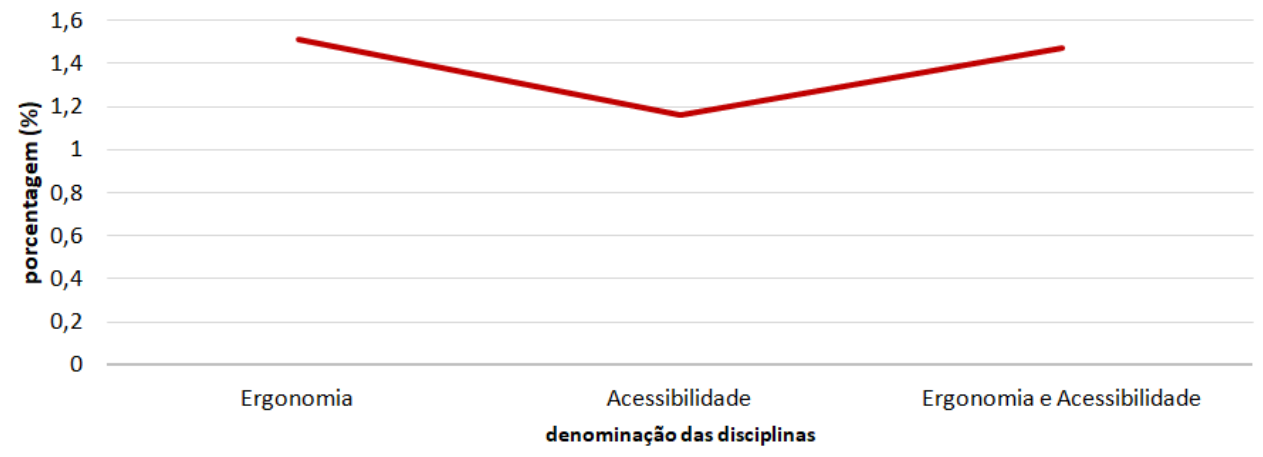

Fonte: dos Autores. 


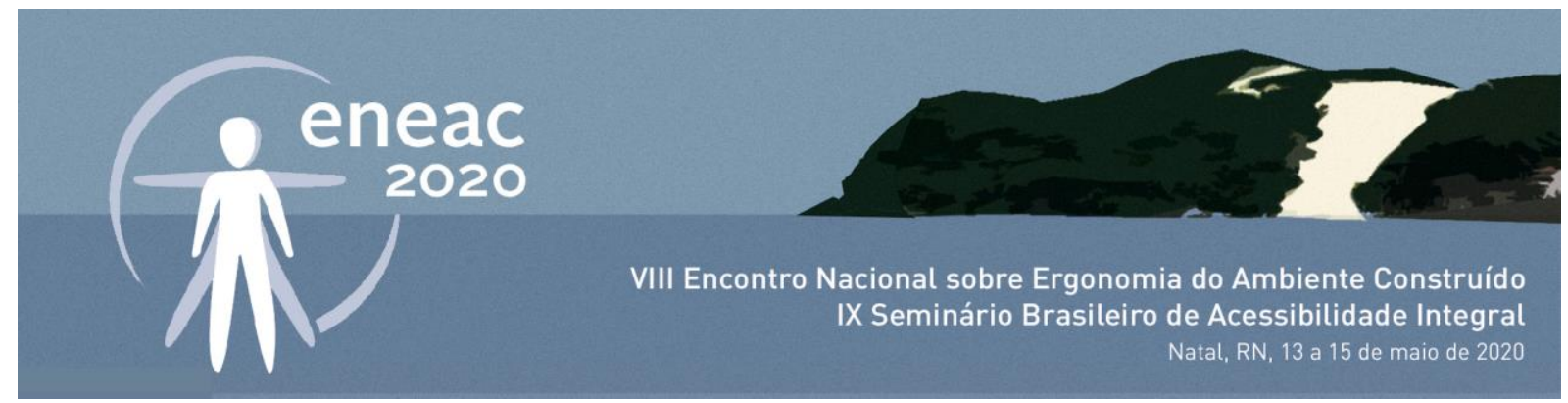

Além disso, percebe-se também (Figura 3) que tais disciplinas, quando abordadas pelos cursos, são ministradas, em maior número de horas, na modalidade eletiva, demonstrando que os discentes podem escolher se irão ou não adicionar tais temas à sua grade curricular.

Figura 3: Porção da carga horária total do curso com relação às modalidades das disciplinas abordadas

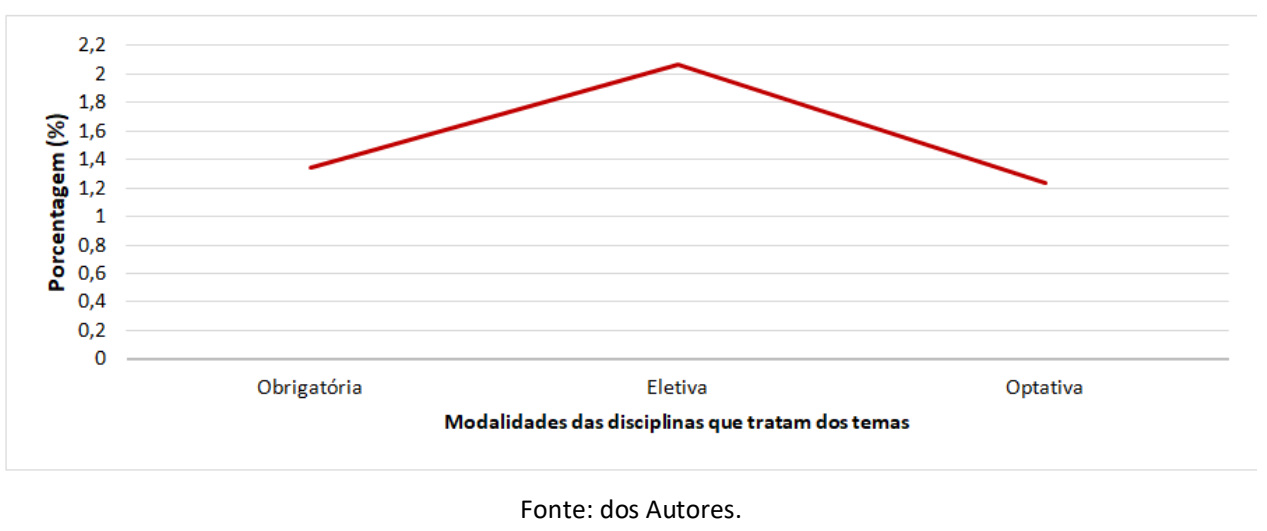

Em uma segunda análise (Figura 4), considerou-se a carga horária média, em horas, de tais temáticas, dividindo-as de acordo com a modalidade ofertada (obrigatória, eletiva e optativa). Diante de tais resultados, observa-se que é destinada uma maior carga horária ao conteúdo sobre ergonomia, que, por sua vez, é, em grande parte, ofertada na modalidade eletiva. Cabe destacar que, na categoria ergonomia e acessibilidade, é possível perceber que a carga horária é maior na modalidade obrigatória, trazendo relevância a esses temas tão importantes para a formação dos futuros arquitetos e urbanistas.

Figura 4: Carga horária média das disciplinas de acordo com sua modalidade

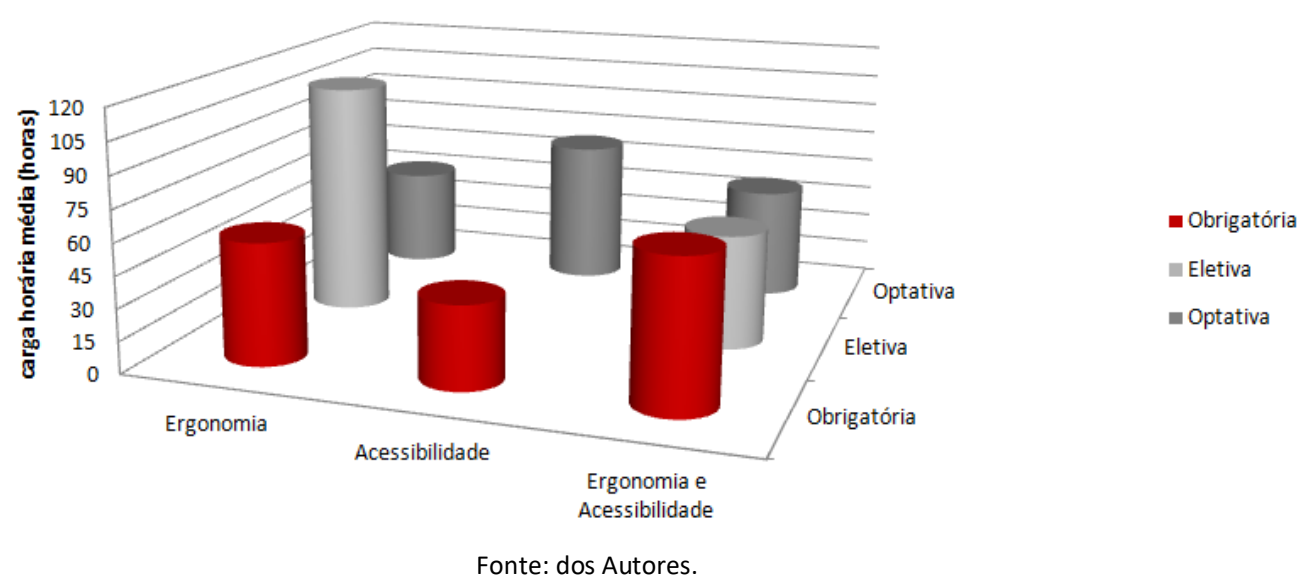

Além disso, através da análise acima (Figura 5), observou-se que, das 65 instituições federais pesquisadas, apenas 26 instituições abordam as temáticas em suas grades curriculares. Esse fato 


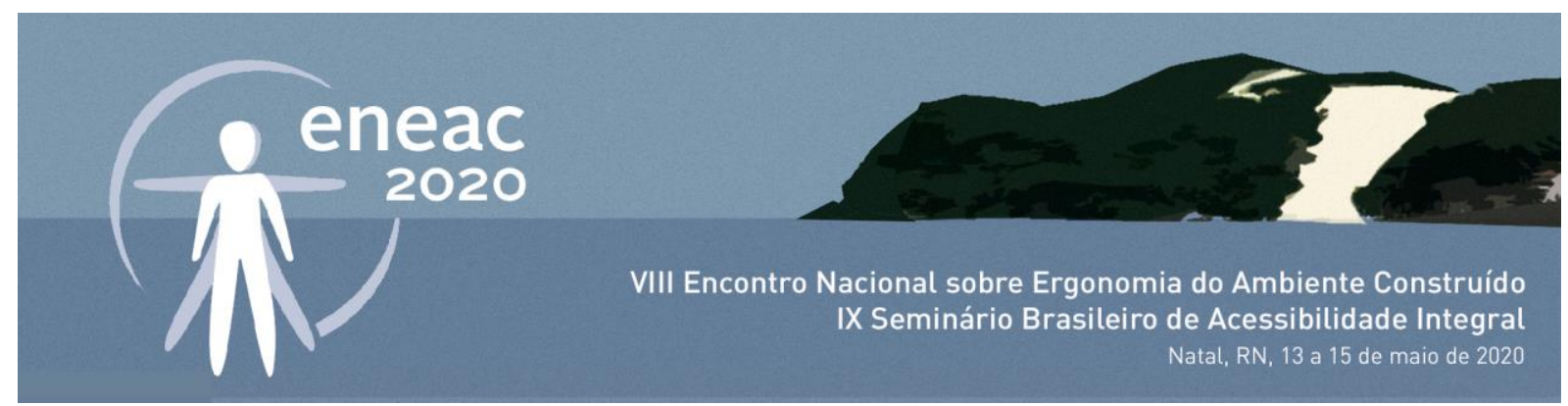

evidencia um déficit na presença de tais assuntos no âmbito pedagógico da maioria das IES de Arquitetura e Urbanismo do país.

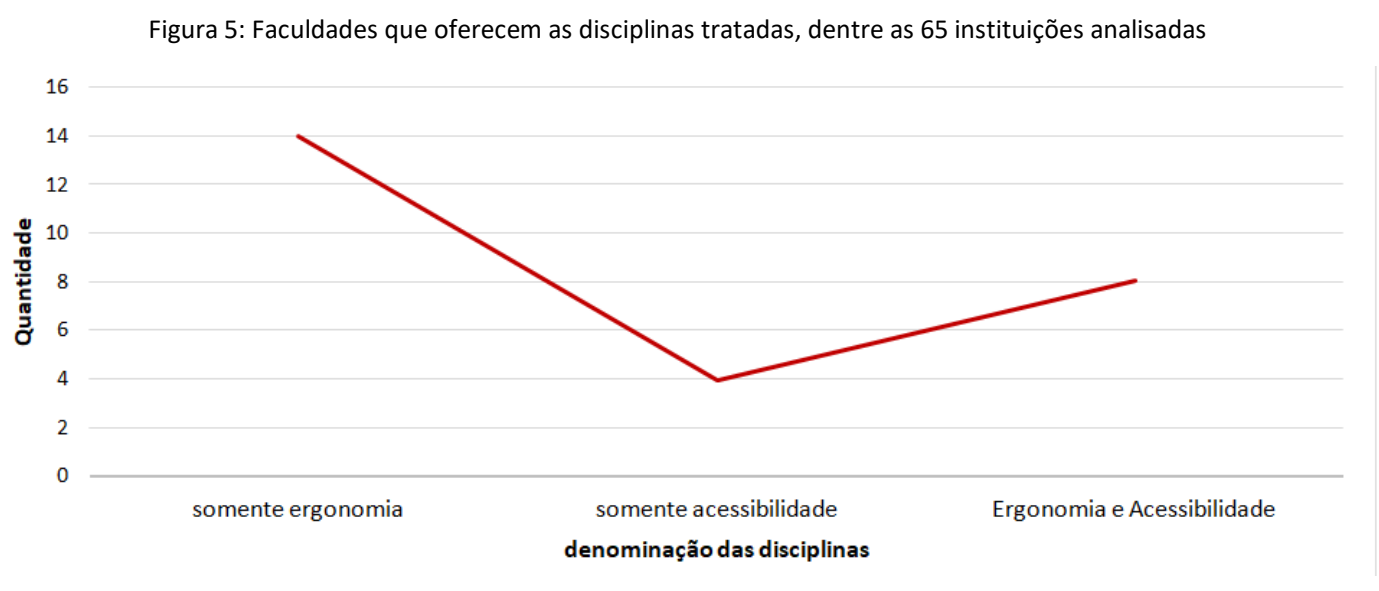

Fonte: dos Autores.

Ademais, no levantamento bibliométrico, foram encontradas 53 obras distintas nas ementas e nos planos de curso das disciplinas de Ergonomia e 97 títulos únicos nas ementas e nos planos de curso das disciplinas de acessibilidade. De uma forma geral, as bibliografias básicas e complementares das disciplinas de ergonomia escolhidas pelos cursos são diversas (em quantidade) quando se analisa o conjunto, mas apresentam limitações, sobretudo na atualidade. No que tange às bibliografias das disciplinas de Ergonomia, a bibliografia mais atual é a de 2015, a NBR ISO 15535 e a NBR 9050, citadas unicamente por quatro instituições.

A partir dos gráficos de tendência linear das publicações (Figuras 6 e 7), é possível apreender uma escolha das publicações a partir de meados dos anos 1990 e início dos anos 2000. Infere-se que esse cenário tenha se dado, sobretudo porque, a partir de 2000, passa-se ter uma maior discussão sobre a pessoa com deficiência e também há uma mudança de uma visão da pessoa com deficiência com maior protagonismo e autonomia, demonstrado pelas várias legislações sancionadas na época, a citar: a lei n 10.098, de 19 de dezembro de 2000, que estabeleceu normas gerais e critérios básicos para a promoção da acessibilidade de pessoas portadoras de deficiência (sic) ou com mobilidade reduzida; a lei $\mathrm{n}^{\circ} 10.048$, de 8 de novembro de 2000 , que deu prioridade de atendimento às pessoas com deficiência; a NBR 9050, de 2004, bem como outras.

A bibliografia mais antiga de Ergonomia identificada nos planos de curso é de 1967, a obra "Les Systemes Hommes-machines", de Montmollin, citada somente por uma instituição. A mais antiga entre as bibliografias de acessibilidade, datada de 1970, é a obra "Defensible Space: Crime Prevention Through Urban Design", de Oscar Newman. 


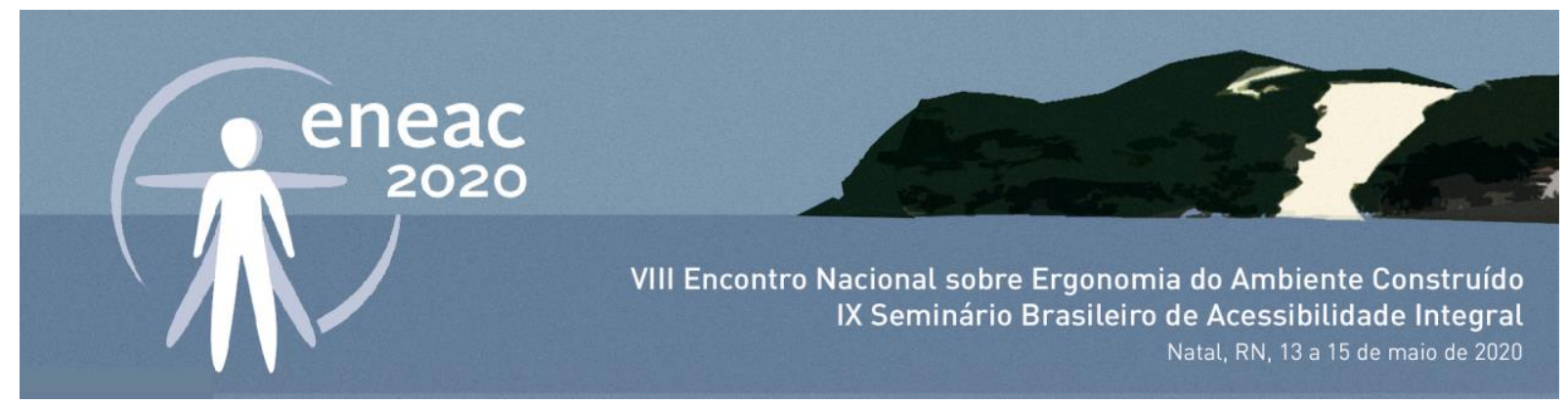

Figura 6: Aparições bibliográficas com bases nos planos de curso por ano sobre a temática Acessibilidade e correlatas

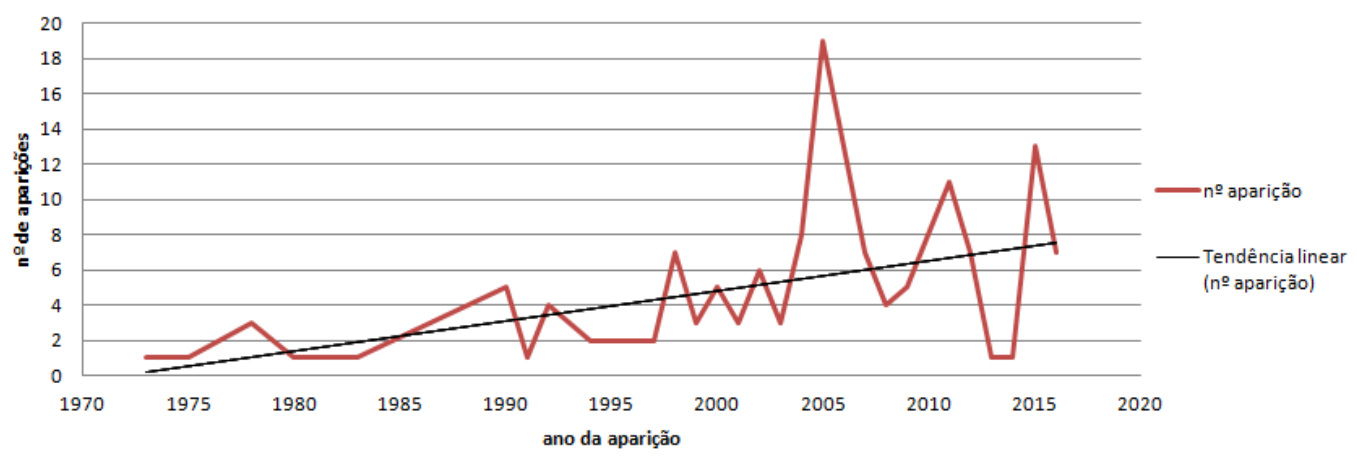

Fonte: dos Autores.

Figura 7: Aparições bibliográficas com bases nos planos de curso por ano sobre a temática Ergonomia e correlatas

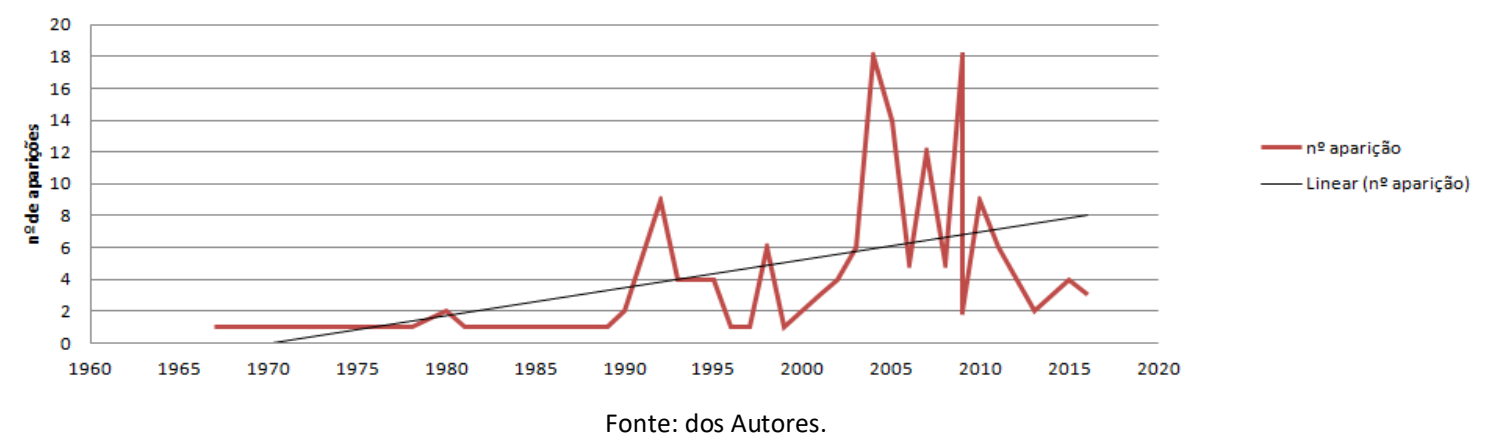

Mais um aspecto de interesse identificado é que grande parte das instituições não trazem nenhuma bibliografia internacional. Dado que a Ergonomia é uma disciplina recente no Brasil, seria importante o embasamento e apresentação de conceitos que estão sendo desenvolvidos em outros países, aumentando, dessa forma, o arcabouço teórico dos discentes.

Ressalta-se que nem mesmo as disciplinas de um estágio mais avançado trazem as referências dos vários exemplares de normas e resoluções importantes para o entendimento técnico do arquiteto e urbanista, a citar: as Norma de Higiene Ocupacional (NHO), a NBR ISO/CIE 8995-1:2013 - Iluminação de ambientes de trabalho e outras que tratam sobre a qualidade do ambiente e a segurança do trabalhoiii aos indivíduos nos ambientes.

Os Quadros 1 e 2 apresentam o resumo do levantamento bibliométrico dos autores utilizados nas bibliografias de Ergonomia e de Acessibilidade. Para ver, na íntegra, as tabelas dos levantamentos bibliométricos dos autores utilizados nas bibliografias de Ergonomia, Acessibilidade e correlatas, acesse: https://encurtador.com.br/jJLOQ. 


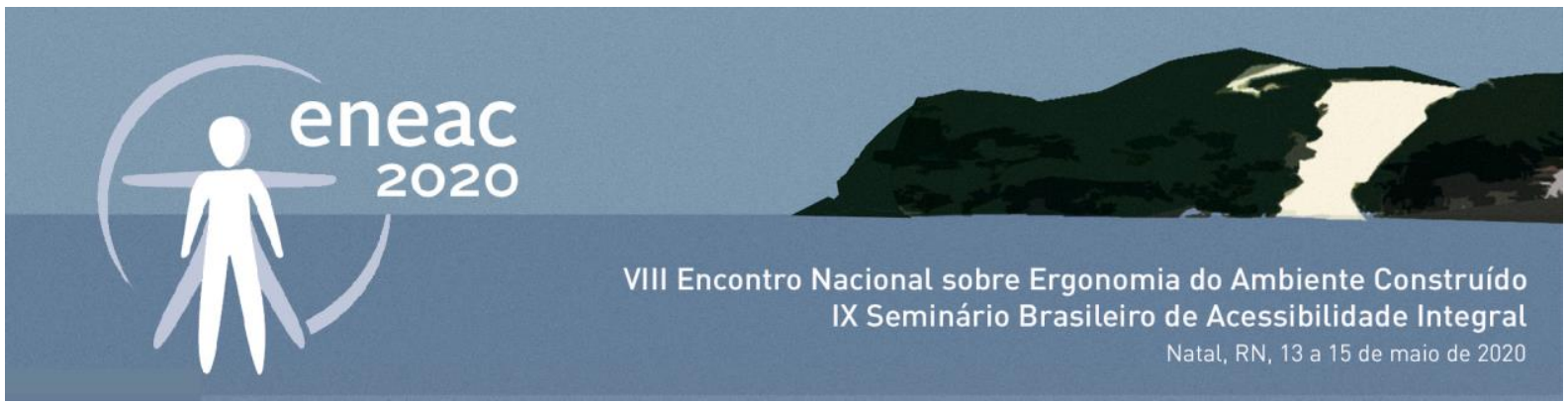

Quadro 1: Resumo do levantamento bibliométrico dos autores utilizados nas bibliografias de Ergonomia e correlatas

\begin{tabular}{|c|c|c|}
\hline $\begin{array}{l}\text { Autores citados de forma muito } \\
\text { frequente } \\
\text { ( } 7 \text { ou mais de } 7 \text { citações em } \\
\text { bibliografias) }\end{array}$ & $\begin{array}{l}\text { Autores citadas de forma } \\
\text { medianamente frequente } \\
\text { (entre } 3 \text { e } 6 \text { citações em } \\
\text { bibliografias) }\end{array}$ & $\begin{array}{l}\text { Autores citadas de forma pouco frequente } \\
\text { (menos de } 3 \text { citações em bibliografias, maior } \\
\text { que } 1 \text { aparição) }\end{array}$ \\
\hline quant. $\quad$ autor & quant. $\quad$ autor & quant. autor \\
\hline lida $(1990,1997,2013,2015$ e & Neufert $(1998,2004$ e 2015) & Prado (2010) \\
\hline 2016) & Mont'Alvão $(1998,2008$ e & Onstein (2010) \\
\hline Abnt (2004 e 2015) & 2011) & Lopes (2010) \\
\hline Grandjean $(1977,1998$ e 2005$)$ & Abrahão (2007 e 2009) & Tillman (1992) \\
\hline Panero $(1987,1996,2002$ & Sznelzar (2007 e 2009) & Sanders (1992) \\
\hline 2003 e 2016) & Silvino (2007 e 2009) & Mc Cornick (1992) \\
\hline & Sarmet (2007 e 2009) & Folz (2003) \\
\hline & Pinho (2007 e 2009) & Gomes (2003) \\
\hline & Cambiaghi (2007) & Gurgel (2003) \\
\hline & Tiley (2007) & Woodson (1992) \\
\hline & & Moraes (1993) \\
\hline
\end{tabular}

Fonte: dos Autores.

Quadro 2: Resumo do levantamento bibliométrico dos autores utilizados nas bibliografias de Acessibilidade e correlatas

\begin{tabular}{|c|c|c|}
\hline $\begin{array}{l}\text { Autores citados de forma muito } \\
\text { frequente } \\
\text { ( } 7 \text { ou mais de } 7 \text { citações em } \\
\text { bibliografias) }\end{array}$ & $\begin{array}{l}\text { Autores citadas de forma } \\
\text { medianamente frequente } \\
\text { (entre } 3 \text { e } 6 \text { citações em bibliografias) }\end{array}$ & $\begin{array}{l}\text { Autores citadas de forma pouco frequente } \\
\text { (menos de } 3 \text { citações em bibliografias, maior } \\
\text { que } 1 \text { aparição) }\end{array}$ \\
\hline quant. $\quad$ autor & quant. autor & quant. autor \\
\hline $\begin{array}{l}12 \text { Abnt }(1990,1993,1999, \\
2000,2002,2004,2007,2010, \\
2013,2015,2016) \\
10 \quad \text { lida } 199,2005 \text { e 2016) }\end{array}$ & $\begin{array}{l}6 \text { Cambiaghi (2007) } \\
5 \text { Panero (2001, 2002 e 2016) } \\
5 \text { Bittencourt (2011) } \\
5 \text { Grandjean (1998 e 2005) } \\
4 \text { Prefeitura Municipal de São Paulo } \\
\text { (1992, 2002, } 2003 \text { e 2005) } \\
4 \text { Neufert (1974 e 2004) } \\
3 \text { Ministério do Trabalho (1978) } \\
3 \text { Mont'Alvão (1998 e 2011) } \\
3 \text { Boueri (1998 e 2008) } \\
3 \text { Lopes (2010) } \\
3 \text { Lanchotti (1998, 2005 e 2014) }\end{array}$ & $\begin{array}{l}2 \text { Dischinger (2009 e 2012) } \\
2 \text { Piandi (2012) } \\
2 \text { Woodson (1992) } \\
2 \text { Tilman, B. (1992) } \\
2 \text { Tillman (1992) } \\
2 \text { Sanders (1993) } \\
2 \text { Mccormick (1993) } \\
2 \text { Resende (2004) } \\
2 \text { Morreira (2011 e 20120 } \\
2 \text { Abrão (2005 e 2009) } \\
2 \text { Henry Dreyless (2005) } \\
2 \text { Stelman (2008) } \\
2 \text { Daum (2008) }\end{array}$ \\
\hline
\end{tabular}

Fonte: dos Autores.

\section{CONSIDERAÇÕES FINAIS}

Este artigo procurou refletir como o ensino da Ergonomia e da Acessibilidade tem se inserido nos currículos dos cursos de Arquitetura e Urbanismo das universidades públicas brasileiras. Conforme pode-se verificar, a Ergonomia e Acessibilidade estão presentes nos currículos, ainda que de forma menos explícita, mas, em sua maioria, esses temas ainda são tratados de maneira bastante elementar, fato revelado principalmente pelas bibliografias não trazerem os principais autores que vêm discutindo sobre as temáticas e também por não trazerem os fundamentais documentos e normas ligadas às disciplinas. 


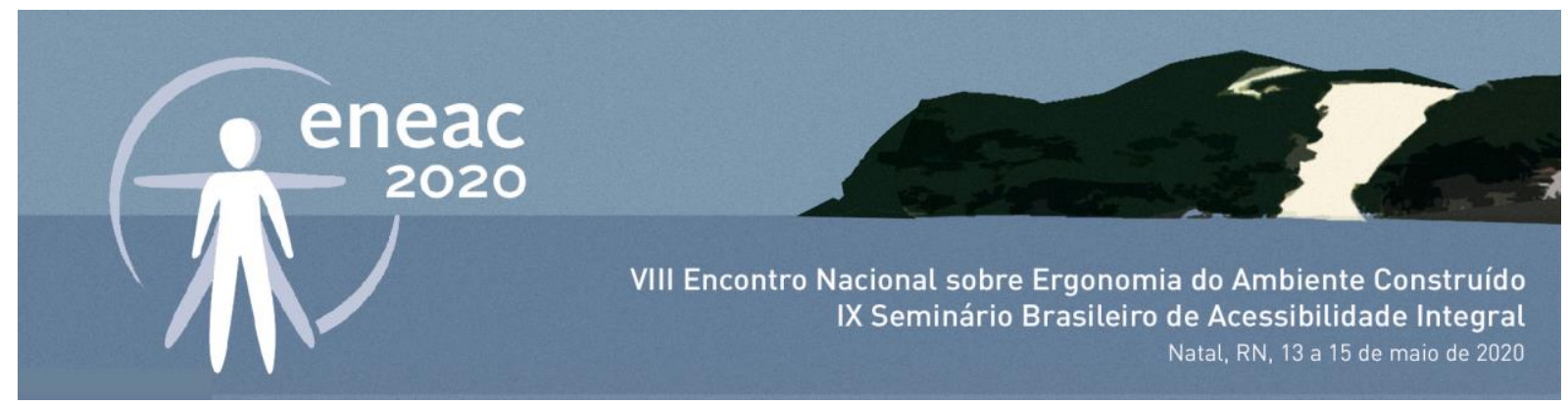

Um ponto positivo encontrado foi que grande parte das instituições tratam a acessibilidade e ergonomia de forma conjunta. Entretanto, percebe-se uma carga horária bastante limitada, o que dificulta a exploração de atividades que enriquecem a formação dos estudantes, como visitas técnicas, atividades de sensibilização, roda de discussão com pessoas com deficiência e especialistas das áreas e outras.

Devido ao fato de esses temas não serem muito aprofundados nos períodos finais dos cursos, é importante pensar no fortalecimento e no desenho de uma educação continuada (curso de aperfeiçoamento, cursos de extensão e outros) que deem conta de formar os profissionais da área, tendo vista a grande demanda do mercado demonstrado pelos dados apresentados neste artigo.

Por fim, diante das discussões levantadas neste artigo, espera-se contribuir, de forma inicial para uma reflexão dos cursos de Arquitetura e Urbanismo quanto às temáticas de Acessibilidade e Ergonomia, bem como sobre a forma pela qual elas têm sido tratadas no currículo de Arquitetura e Urbanismo. Além disso, este artigo busca contribuir com a apresentação da bibliografia sobre Acessibilidade e Ergonomia mais recorrente nos planos de curso.

Como estudos futuros, indica-se se abranger as escolas particulares e se aprofundar nas demais formas que acontece a educação universitária, como os projetos de pesquisas, projetos e ações de extensão e as atividades de inovações nas quais essas temáticas são abordadas.

\section{AGRADECIMENTOS}

À Pró-Reitoria de Extensão da Universidade Federal de Juiz de Fora, pelo financiamento do projeto de extensão (concessão de bolsas), dentro do qual algumas questões trazidas neste artigo são constantemente discutidas.

\section{REFERÊNCIAS}

ABRAHÃO, J. I.; PINHO, D. L. M. As transformações do trabalho e desafios teórico-metodológicos da Ergonomia. 2002. Disponível em: http://www.scielo.br/pdf/epsic/v7nspe/a06v7esp.pdf. Acesso em: 10 dez. 2019.

ALONSO, P.; FREIRE, S.; PANET, A. Acessibilidade - uma vivência necessária. In: SEMINÁRIO INTERNACIONAL NUTAU, 7., São Paulo, 2008. Anais... São Paulo: USP, 2008. Disponível em: https://www.usp.br/nutau/CD/158.pdf. Acesso em: 26 dez. 2019.

ASSOCIAÇÃO BRASILEIRA DE ERGONOMIA. O que é Ergonomia. [s.d.]. Disponível em: http://www.abergo.org.br/internas.php?pg=o_que_e_ergonomia. Acesso em: 12 dez. 2019.

ASSOCIAÇÃO BRASILEIRA DE NORMAS TÉCNICAS. NBR 9050: acessibilidade a edificações, mobiliário, espaços e equipamentos urbanos. Rio de Janeiro: ABNT, 2004; 2015.

BARBOSA, M.L. A.; GUIMARÃES, Lia Buarque M. A Ergonomia como disciplina nos cursos de Design e Arquitetura em Curitiba. Estudos em Design, v. 17.1, p. 1-24, 2009. Disponível em: encurtador.com.br/irTX0. Acesso em: 5 fev. 2020.

BRAIDA, F.; RAPOSO, M.; RIBEIRO, J.; CAVALARI, K. Três níveis de engajamento dos pesquisadores nos projetos de rotas acessíveis. In: MONT'ALVÃO, C.; VILLAROUCO, V. (Orgs.). Um novo olhar para o projeto, 2: a ergonomia no ambiente construído. Recife: Editora UFPE, 2014. p. 163-180.

BRASIL. Ministério da Cidadania. Secretaria Especial do Esporte. Acessibilidade na Copa 2014 é questão central para Ministério do Esporte. 2011. Disponível em: encurtador.com.br/ouwF8. Acesso em: 5 dez. 2019. 


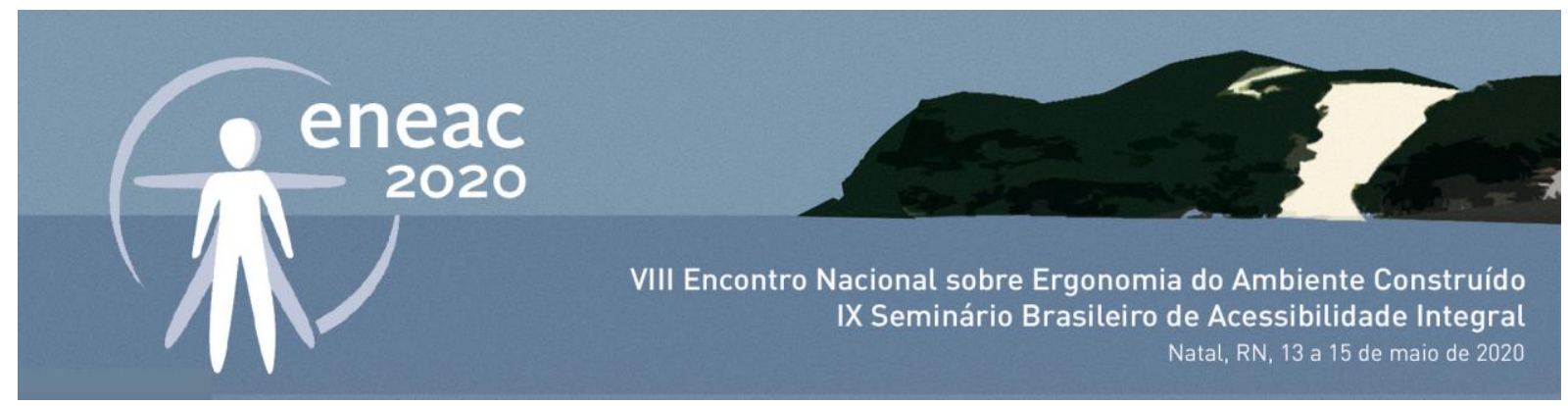

BRASIL. Ministério da Educação. Resolução no 2, de 17 de junho de 2010. Brasília: MEC, 2010. Disponível em: encurtador.com.br/PZ168. Acesso em: 5 fev. 2020.

CASTRO, I. S.; RHEINGANTZ, P. A. Projetar e ensinar mais próximo da realidade: uma abordagem sob o ponto de vista da ergonomia. In: PROJETAR 2005. Anais do II Seminário sobre Ensino e Pesquisa em Projeto de Arquitetura. Disponível em http://prolugar.fau.ufrj.br/arq_pdf/diversos/artigos_iara/projetar_ensino. Acesso em: 10 dez. 2019.

CONSELHO DE ARQUITETURA E URBANISMO DO BRASIL. Anuário de arquitetura e urbanismo. Brasília, DF: CAU/BR, 2019. Disponível em: encurtador.com.br/ikyBS. Acesso em: 10 jan. 2020.

CONSELHO DE ARQUITETURA E URBANISMO DO BRASIL. Resolução no 162, de 24 de maio de 2018. Diário Oficial da União: seção 1, n. 116. Brasília, 19 jun. 2018. p. 105. Disponível em: encurtador.com.br/cKQ07. Acesso em: 05 jan. 2020.

CORRÊA, R. M. (Org.). Avanços e desafios na construção de uma sociedade inclusiva. Belo Horizonte: Sociedade Inclusiva/PUC-MG, 2008.

DISCHINGER, M.; BINS ELY, V. H. M. Promovendo acessibilidade nos edifícios públicos: guia de avaliação e implementação de normas técnicas. Santa Catarina: Ministério Público do Estado, 2006.

ENCONTRO NACIONAL SOBRE ENSINO DE ARQUITETURA E URBANISMO, 37., 2019, Rio de Janeiro. Desafios do ensino de arquitetura e urbanismo no século XXI. Rio de Janeiro: UVA; Abea, 2019. Disponível em: encurtador.com.br/yLZ03. Acesso em: 10 jan. 2020.

GURGEL. M. Projetando espaços: guia de arquitetura de interiores para áreas residenciais. 3. ed. São Paulo: Senac, 2002.

INSTITUTO DOS ARQUITETOS DO BRASIL. Duzentos anos do ensino de arquitetura no Brasil: história e reflexões. 2016. Disponível em: encurtador.com.br/hpzK5. Acesso em: 8 jan. 2019.

MORAES, M. C. de. Acessibilidade no Brasil: análise da NBR 9050. 2007. Disponível em: https://core.ac.uk/download/pdf/30371587.pdf. Acesso em: 26 dez. 2020.

MORAES, A. de; MONT’ALVÃO, C. Ergonomia: conceitos e aplicações. 4a. ed. Teresópolis: Editora 2AB, 2012.

PREFEITURA do Rio divulga ações de acessibilidade para os Jogos Rio 2016: cidade ganhará $4.000 \mathrm{~m}^{2}$ de calçadas acessíveis e $5.831 \mathrm{~m}^{2}$ de pavimento em concreto na entrada de principais atrações turísticas. Rede Nacional do Esporte. 2015. Disponível em: encurtador.com.br/hxzO4. Acesso em: 05 dez. 2019.

ROSA, C. L. da S.; BRAIDA, F.; COBUCCI, N. A cultura da inclusão social no território da universidade: um olhar sobre a acessibilidade a partir de uma perspectiva da indissociabilidade entre o ensino, pesquisa e extensão. Revista Científica ANAP Brasil, [S.I.], v. 12, n. 25, dez. 2019. Disponível em: encurtador.com.br/hDQ23. Acesso em: 10 fev. 2020.

SHIMOSAKEI, R. COL amplia acessibilidade para pessoas com deficiência na Jornada Mundial da Juventude. Turismo Adaptado. 2013. Disponível em: encurtador.com.br/axGSU. Acesso em: 10 jan. 2020.

\section{NOTAS}

' Ressalta-se que somente mencionamos a figura do arquiteto, e não, a do urbanista também, pois o urbanismo, no Brasil, enquanto cadeira/ensino formal, surgiu com a Universidade do Distrito Federal em 1935, após tentativas anteriores não sucedidas de inclusão da disciplina nos cursos de arquitetura (INSTITUTO DOS ARQUITETOS DO BRASIL, 2016).

ii Reforça-se que as análises e os resultados alcançados decorreram dos dados coletados nos PPC dos cursos. Assim, parte dos dados pode não corresponder à realidade, caso a prática das instituições não reflitam os documentos oficiais públicos disponíveis para consulta.

iii Segundo a resolução № 162, de 24 de maio de 2018, a "habilitação para o exercício das atividades de especialização em Engenharia de Segurança do Trabalho pelos arquitetos e urbanistas dependerá de registro profissional ativo e do registro do título complementar de "Engenheiro (a) de Segurança do Trabalho (Especialização)" em um dos Conselhos de Arquitetura e Urbanismo dos Estados e do Distrito Federal (CAU/UF), nos termos desta Resolução" (CONSELHO DE ARQUITETURA E URBANISMO DO BRASIL, 2018). 